\title{
ROLE OF CASE SCENARIOS IN IMPROVING EFFECTIVENESS OF LARGE GROUP LECTURE FORMAT: DATA FROM UNDERGRADUATE MEDICAL STUDENTS
}

\author{
Maria Safdar \\ Demonstrator \\ Department of Forensic Medicine, CMH Lahore Medical College, \\ Punjab, Pakistan \\ E-mail: mariasafdar79@gmail.com

\section{Zahid Farooq Baig} \\ Professor \\ Department of Medicine, CMH Lahore Medical College, \\ Punjab, Pakistan, \\ E-mail: zhd.frq@gmail.com
}

\section{Attia Sheikh}

Associate Professor

Department of Medical Education, CMH Multan Institute of Medical Sciences,

Punjab, Pakistan

E-mail: attiasheikh@hotmail.com

\begin{abstract}
Teaching practices are being modified over time to more student centered approaches to improve the learning. Lecture being the corner stone of the teaching, need techniques to improve its effectiveness thus emphasizing "learning" rather than "teaching." One of the main problems with long lectures is the low attention span of students. This study was undertaken to assess the role of adding case scenarios to the lectures, thus improving its learning outcomes. It is a descriptive study conducted in $3^{\text {rd }}$ year and $4^{\text {th }}$ year students at CMH Multan Institute of Medical Sciences (CIMS) from $1^{\text {st }}$ October 2018 to $1^{\text {st }}$ April 2019. The focus of this study was to know impact of case scenarios in improving learning of the students in a lecture. During study period, on average two lectures per months of department of medicine, were taken with addition of case scenarios. The outcome measurement of this technique was done by two methods, feedback by the students and peer review from colleagues. There were a total of 61 participants who gave feedback on the lecture. Analysis of feedback performa revealed that almost $64 \%$ of students had a low attention span
\end{abstract}


$\overline{\text { after } 20 \text { minutes into a well prepared and interesting lecture. Fifty to } 90 \text { percent of }}$ students agreed or completely agreed that adding aids like videos, graphics, algorithms or case scenarios etc improved the learning of students. More than ninety percent of participants completely agreed or agreed that the case scenarios are relevant, provide sufficient information, improve learning outcome and serve the purpose. The second part of the data collection was peer review; five colleagues attended the lectures during this period and in addition to filling feedback performa, gave valuable reviews on this. All the peers supported the idea of using case scenarios during lectures. We can conclude that adding case scenarios to the large group lecture format makes it more interactive, improved attention span and keeps attention of students which is difficult to achieve in a class of almost hundred.

\section{KEYWORDS}

Case scenario, Lecture, Learning outcome, Medical Students

\section{INTRODUCTION}

Since the advent of adult education, teachers have realized that learners need to see the relevance and be actively involved in the topic being studied (Knowles, 2005). Thus the teaching practices have been modified over time with additions of more interactive techniques like problem based learning and case based learning but still lectures often remain the corner stone of teaching. They can be an effective method for communicating theories, ideas and facts to students. Lectures provide an economical and efficient method for delivering substantial amounts of information to large numbers of student especially in resource poor countries like Pakistan. The problem with large group lecture format is that student attention span declines precipitously after 10 to 15 minutes which adds to poor retention (Bradbury, 2016). This can be handled breaking the lecture in small segments and adding a suitable activity involving students, after every 10 to 20 minutes, in order to reset the attention span. Adding case scenarios to the lectures helps exposure to clinical work early and thus mixing of basic and clinical sciences. This is known as vertical integration and in present time medical education it is considered important (Eisenstein, 2014).

\section{LITERATURE REVIEW}

To improve the learning outcome the teaching is slowly shifting from teacher centered approach to student centered approach and case based learning (CBL) is becoming one of the most commonly used student centered approach. CBL helps develop critical thinking, problem solving, clinical reasoning and analysis in the students. Pearson et al (2003) concluded that the innovative CBL paradigm is an 
effective adjunct to the traditional lecture format. The study by Kassebaum et al (1991) was able to demonstrate that CBL made the learning more enjoyable.

A comparison of these CBL with traditional lectures has been carried out in many studies. Marantz PR et al (2003) revised the course in epidemiology and biostatistics to use the case-discussion teaching method instead of traditional lectures. The evaluation was done by using subjective faculty feedback, examination scores and student evaluation questionnaires. They found out that the student evaluation was overwhelmingly positive and it had significant improvement compared to previous years of the course with traditional lecture curriculum.

Meo SA (2013) carried out study in 2 undergraduate medical schools, one medical school followed traditional lecture based curriculum and the other problem based learning (PBL) curriculum in respiratory physiology. At the completion of study period assessment was done with single best multiple choice question and skill was measured based on the objective structured practical examination. Students in the PBL group obtained significantly higher knowledge and skill scores in the respiratory physiology course compared with students in the traditional style of medical schools.

Latif R (2014) compared performance of medical students in vascular physiology module of traditional lectures with CBL. The student performance was evaluated by comparing exam scores between the two classes. Although there were two different groups of students but the rest including text, instructor, assignments and exam paper were same. She found out that there were significant differences between average exam scores immediately and 2 months after course completion.

Many studies like these have proved that CBL curriculum is better than traditional lectures with significantly better assessment results. The problem with CBL is that it is most effective as a small group teaching tool; it is time as well as resource intensive and will require complete revamping of the current syllabus (Sharma, 2017). The role of traditional lectures cannot be undermined by this and it is still the most predominant form of teaching in medical education. In the study by Kassebaum et al (1991) the lecture format produced an interesting result; students felt the lecture method was more helpful in preparing for a written exam.

We need to implement some innovative techniques to improve our lecture-based teaching which can be reasonably applied within our framework. There is no substitute to a well prepared lecture as student like good lectures. Breaking up teacher's talk time in chunks of 15 to 20 minutes improves lecture quality. This time can be used for student's participation to work on a problem, talk about what they have just heard or a small video clip which explains your point etc. One approach 
that can be used in our current setup is the judicious use of scenarios as a supplement to traditional lecture-based sessions (Sharma, 2017). Case scenarios are especially helpful for medical students who can understand the practical application of the theory they have just studied and thus help them connect to the real world. By using case scenarios in traditional lecture you produce a hybrid system in between traditional lecture and CBL. The term "scenario-based learning" refers to any educational approach that involves the use of scenarios to bring about desired learning intentions (Bloomfield, 2009; Errington, 2005). This helps getting good points of both methods, on one hand we are able to provide a good overview of a topic and on the other hand connect it to CBL techniques by discussing different scenarios with the students helps develop critical thinking, problem solving, clinical reasoning and analysis in the students, thus makes students to understand its practical application.

The traditional lectures are criticized for its effectiveness because of deteriorating attention span of the participants and there is also a lot of discussion about the exact attention span (Knowles, 2005). One of the most important effects of adding case scenario after every 15 to 20 minutes breaks the lectures in small portions and students' participation during this time improves their attention span.

\section{RESEARCH OBJECTIVE}

1. What is the attention span of our medical students during well prepared traditional lecture?

2. Addition of other aids like info graphics, teaching videos, flow charts, adding learning outcomes and take home messages improve learning outcome of students

3 . Addition of case scenarios improve the understanding of the lectures

\section{RESEARCH HYPOTHESIS}

1. Attention span in our students is different from other regions in the world

2. Using additional aids like info graphics, teaching videos, flow charts, take home messages during lectures improve learning.

3. Adding case scenarios to traditional lectures is relevant, provides sufficient information, improves learning outcome and serves the purpose

\section{RESEARCH METHODOLOGY}

In CIMS we are required to give 50 minutes lectures to a class of almost 100 students. There are 3 lectures of internal medicine per week; two for $4^{\text {th }}$ year MBBS and one for $3^{\text {rd }}$ year MBBS, every consultant from the department of medicine delivers around two lectures per month. To enhance students learning we planned to 
break the lecture in small segments with a small discussion every 10 to 20 minutes so that attention of students can be readjusted and lecture continued. During this break we have been trying different things individually or in combination including info graphics, teaching videos, algorithms and case scenarios.

Case Scenarios were prepared to ensure that they met the learning outcomes of that lecture. One of the students reads the scenario loud and then the class was encouraged to actively participate in the discussion. By doing this the class once again becomes active and involved in the lecture. This also provides a link of theory being taught to them with a clinical environment which they face in hospitals. Clinical topics must always be case and patient oriented to give students better understanding about the disease.

\section{Outcome measures}

The outcome measurement of adding case scenarios to the lectures was done by two methods, feedback by the students and peer review from colleagues.

\section{Feedback Performa}

Students' feedback performa was very simple and had only 3 questions making it easy for students to answer and not involve them in unnecessary details. The questions of feedback included following:

1.1. What is your attention span of an interesting and well prepared lecture?

1.2. What additional measures improve your learning in lectures?

1.3 Comments on case scenarios.

\section{Peer Review}

The second part of the data collection was peer review; the lectures were attended by five of my colleagues, feedback was taken about this style of lecture and whether this improved the learning of participants. The three main questions about the lecture included:

2.1. In what way was this an experience in which the students were actively learning?

2.2. Was there any particularly innovative or excellent practice?

2.3. To what extent were the learning outcomes/intentions of the session achieved?

\section{DATA ANALYSIS AND RESULTS}

\section{Feedback}

There were a total of 61 participants who gave feedback on the lectures. As per our data more than sixty percent will have a low attention after 20 minutes so we need to alter the lecture to reset their attention and then proceed with the lecture. (Figure-1). 


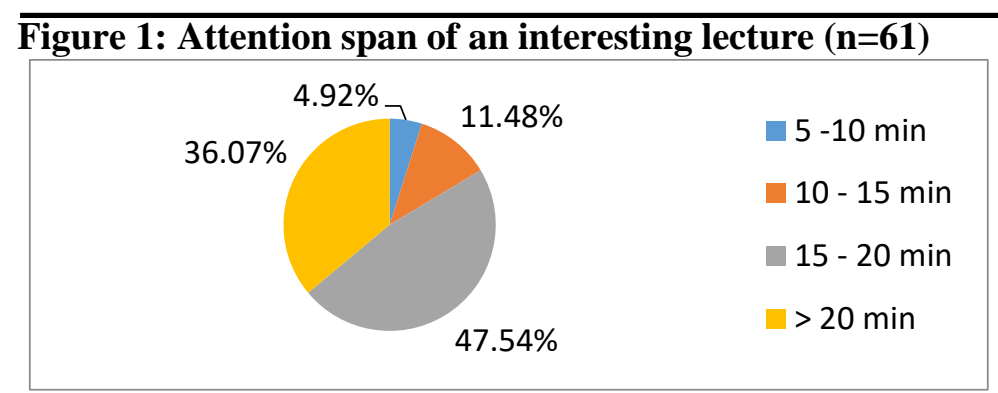

There are a total of 61 participants in this pie-chart. Only around $36 \%$ of students had attention after 20 minutes into an interesting and well prepared lecture and almost $64 \%$ of students lack attention after 20 minutes

The second question was about additional aids which improve learning in a lecture and it is interesting to know from the data, that students have mostly encouraged additional aids like graphics, videos and case scenarios etc to the lecture (Figure-2).

\section{Figure 2: Impact of additional aids on lecture $(n=61)$}

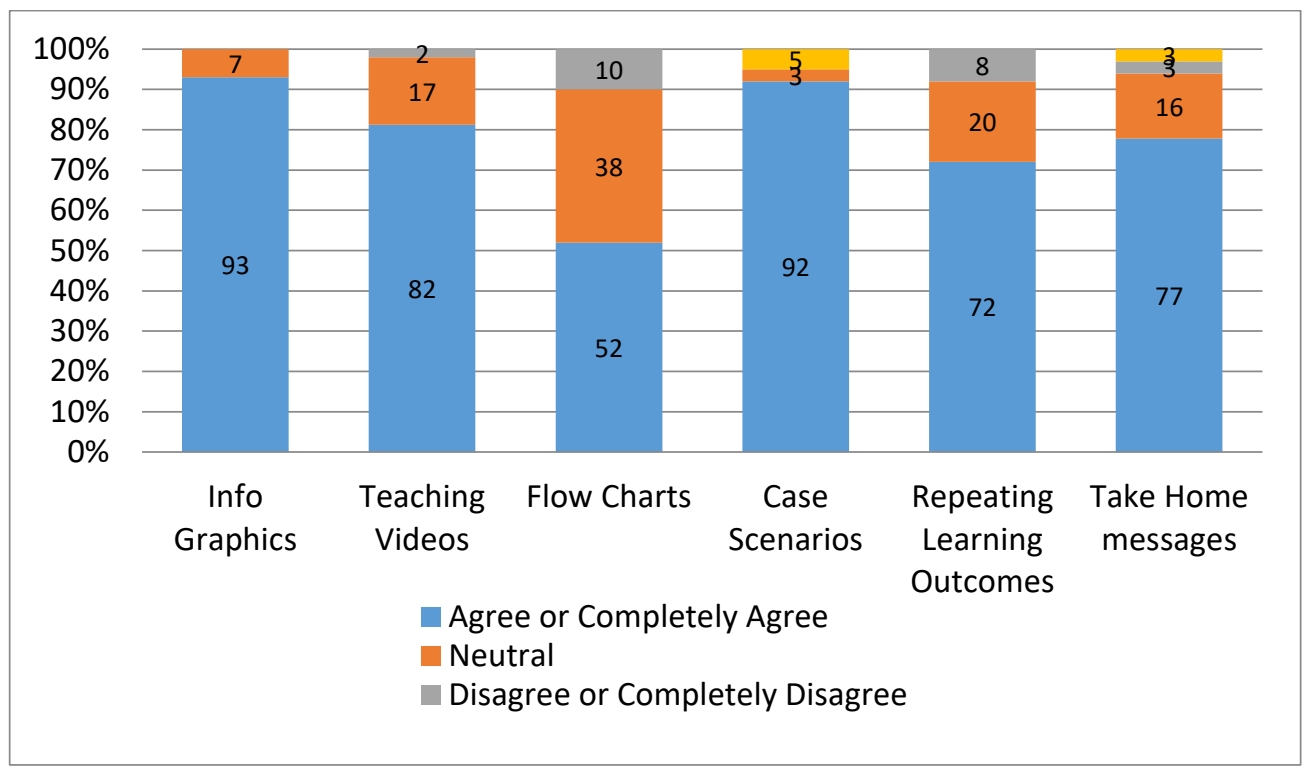

There are a total of 61 participants in this graph. It shows that majority of students supported the use teaching aids during long lectures. Over $90 \%$ students agreed or completely agreed with the use of info graphics and case scenarios in lectures. Use of 
teaching videos during lectures, repeating learning outcomes and showing take home at the end of lectures was advocated by vast majority i.e. $72 \%, 77 \%$ and $82 \%$ respectively. Minimum support was received by flow charts to which only $52 \%$ students agreed or completely agreed recommending their use while the rest were neutral or disagreed with their use.

Over sixty-seven percent of participants completely agreed that case scenarios improved the learning in lecture which was the highest for any other aid of learning; this was followed by repeating learning outcomes at the end of the lectures $(50.82 \%)$ and info graphics (45.90\%).

The third question was on importance of case scenarios in improving the understanding of the lectures. The response on this question was overwhelmingly positive showing that more than ninety percent of participants completely agreed or agreed that the case scenarios are relevant, provide sufficient information, improve learning outcome and serve the purpose (Figure-3).

Figure 3: Case scenarios $(n=61)$

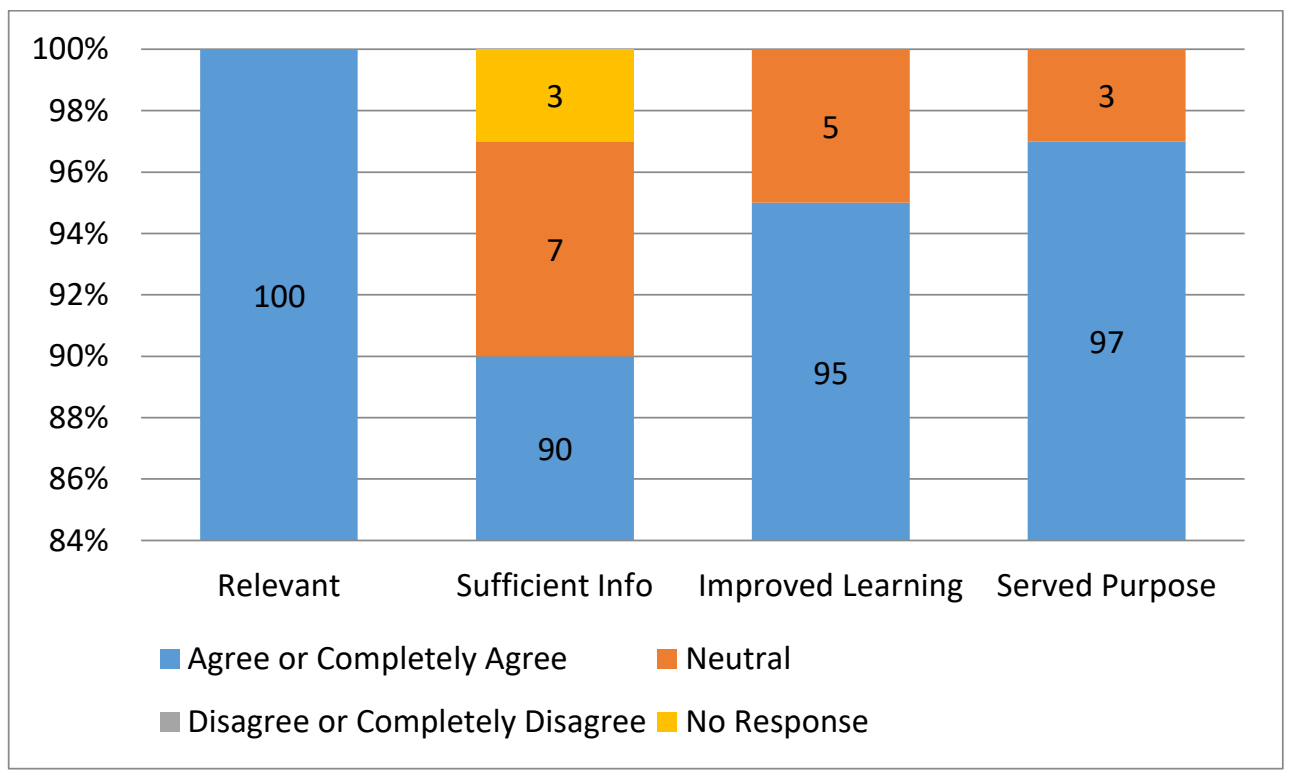

There are a total of 61 participants in this graph. This graph shows that use of case scenarios was supported almost all students and not even a single students disagreed with its use. All students (100\%) agree or completely agree that they are relevant and 
a vast majority agree or completely agree that they provide sufficient information (90\%), improve learning (95\%) and served the purpose (97\%) in the lecture.

\section{Peer review}

All my colleagues supported the idea of using case scenarios during lectures. They considered it interactive with active involvement of students and improve critical thinking. Use of case scenarios helps the students to know about the clinical application of theoretical knowledge and breaking down lecture in case scenarios and involving students was considered to be an excellent practice. The students were encouraged to come up with their ideas and learning outcomes were well achieved.

One of the comments by Professor and a very senior colleague is "the scenario based problems accelerated the thinking process of the students and caught attention throughout the lecture showing the highest level of educational skills of teaching."

\section{CONCLUSION AND DISCUSSION}

The study aimed at 3 important questions, firstly attention span of our students and we can conclude from our study that more than sixty percent will have a low attention after 20 minutes. The deteriorating attention span of students is one of the main drawbacks of traditional lectures, but it also varies depending upon how interesting the lecture is and the teaching skills of the instructor. As per feedback from our students, their attention span is a bit higher than international data with a total span of 10 to 15 minutes (Benjamin, 2002; McKeachie,1986; Svincki, 2013). A study by Stuart et al (1978) showed that attention rose rapidly during the first 10 to 20 minutes and then slowly and steadily declined until the end of the 50 minutes lecture. The calculation of attention span in our students' was done through feedback performa while studies being compared used other sources to calculate the attention span and this may be one of the reasons for the difference. With an attention span of less than 20 minutes in our students, we need to alter the lecture to reset their attention and then proceed with the lecture.

The second question was about use of additional aids in traditional lectures. The students have mostly encouraged additional aids like graphics, videos and case scenarios etc to the lecture. The third question on the use of case scenarios was supported by vast majority of participants and that they are relevant, provide sufficient information, improve learning outcome and serve the purpose. Robert Gagne is considered to be one of the foremost contributors to the systematic approach to instructional design and his theory has provided a great number of valuable ideas for trainers and teachers (Khadjooi, 2001). Case scenarios are the best ice breakers and also attention grabbers thus justifying Gagne principles. Adding aids 
like video, demonstration, lecture, podcast, group work and case scenarios can help chunk/divide the lecture and thus help improve the learning process. In our study majority of students agreed or completely agreed that adding learning aids improve the lecture quality and over $90 \%$ supported the use of case scenarios and info graphics in the lectures.

Students have better learning when teaching includes explanation from examples so the use of case scenarios can therefore be very effective in the lectures (Dunne, 2004). The major advantage of teaching with scenarios is the active involvement of students in analysis from the examples. This provides enough information for the students and then to identify how to apply those solutions in other similar situations. This has been complemented in our study with 90 percent of students supporting its use in lectures, considering it relevant which provide sufficient information, improve learning and serve the purpose of teaching. Peer review was also very encouraging who supported the idea of adding case scenarios to the lectures. It improved students participation, critical thinking and gave them a clinical touch about the subject.

Sharma et al (2017) studied the effect of scenarios in increasing the effectiveness of lecture-based sessions in pharmacology teaching of MBBS students. The results of this study are very similar to our study and vast majority of student supporting the use of case scenarios in the lectures. In this study 94 percent of students considered case scenarios addition to lectures as interesting and student oriented, 89 percent thought that these are interactive and increase attention span and 85 percent commented that it improved understanding of concept and critical thinking. There is a slight difference in methodology in the studies that they used case scenarios in the last 15 minutes of the lectures and we spaced these scenarios in the lecture. I am more in favour of our technique as it divides the lectures in chunks and a discussion every 15 to 20 minutes helps readjust attention span of the students.

Bradbury (2016) nailed the concept that variability of students attention span is not due to difference in teaching formats but it arises from differences between the teachers. ${ }^{3}$ It is teachers' job to enhance his teaching skills, prepare the lecture as per students requirements and present it in an interesting way which is most satisfying for the students.

\section{RECOMMENDATIONS}

The study was organized to see impact of adding case scenarios to the large group lecture on improving learning outcome in undergraduate medical students. The attention span of our students was a bit higher when compared with international data. Such format makes it more interactive, improves attention span and keeps attention of students which is difficult to achieve in a class of almost hundred. Case 
scenarios are best ice breakers and attention grabbers. Using case scenarios in clinical lectures improves students' participation; promote critical thinking and problem solving skills. Clinical topics must always be case or patient oriented and would be incomplete without proper examples. Adding other aids like info graphics, teaching videos, flow charts, learning outcomes and take home messages was supported by majority of students.

\section{REFERENCES}

Benjamin, L.T. (2002). Lecturing. In Davis, S.F., Buskist, W. (Eds.), The Teaching of Psychology: Essays in Honor of Wilbert J. MaKeachie and Charles L. Brewer (pp. 57-67). Mahwah, NJ: Lawrence Erbaum Associates, Inc.

Bloomfield, L., Magney, A. (2009). Does facilitator expertise matter? A perspective from scenario-based learning question. Focus Health Prof Educ Mult Disciplinary $J, 10(3), 1-12$.

Bradbury, N.A. (2016). Attention span during lectures: 8 seconds, 10 minutes, or more? Adv Physiol Educ, 40, 509-513.

Dunne, D., Brooks, K. (2004). Teaching with Cases. Halifax, NS: Society for Teaching and Learning in Higher Education.

Eisenstein, A., Vaisman, L., Johnston-Cox, H., et al. (2014). Integration of basic science and clinical medicine: the innovative approach of the cadaver biopsy project at the Boston University School of Medicine. Acad Med, 89(1), 50-52.

Errington, E. (2005) Creating Learning Scenarios; A Planning Guide for Adult Educators. Palmerston North, NZ: Cool Books.

Kassebaum, D., Averbach, R., Fryer, G. (1991) Student preference for a case-based vs. lecture instructional format. J Dent Educ, 55(12), 781-784.

Khadjooi, K., Rostami, K., Ishaq, S. (2001). How to use Gagne's model of instructional design in teaching psychomotor skills. Gastroentrol Hepatol Bed Bench, 4(3), 116119.

Latif, R. (2014). Impact of case-based lectures on students' performance in vascular physiology module. Adv Physiol Educ. 38(3), 268-372.

Marantz, P. R., Burton, W., Steiner-Grossman, P. (2003). Using the case-discussion method to teach epidemiology and biostatistics. Acad Med. 78(4), 365-371.

McKeachie, W. J. (1986). Teaching Tips: Strategies, Research and Theory for College and University Teachers. Lexington, MA: Heath.

Meo, S. A. (2013) Evaluating learning among undergraduate medical students in schools with traditional and problem-based curricula. Adv Physiol Educ. 37(3), 249-253. 
PJER, Vol 4, Issue 3 (2021)

Augmenting the teacher...

Knowles, M.S., Holton, E.F., Swanson, R. A. (2005). The Adult Learner: The Definitive Classic in Adult Education and Human Resource Development. Boston: Taylor and Francis Ltd.

Pearson, T., Barker, W., Fisher, S., et al. (2003). Integration of the case-based series in population-orientated prevention into a problem-based medical curriculum. Am J Prev Med. 24(4), 102-107.

Sharma, S., Dahiya, N. (2017). Use of scenarios to increase the effectiveness of lecture-based sessions in pharmacology. Natl J Pharm Pharmacol. 7(5), 517-521.

Stuart, J., Rutherford, R.J. (1978). Medical students concentration during lectures. Lancet, 312, 514-516.

Svincki, M.D., McKeachie, W. J. (2013). McKeachie's Teaching Tips: Stretegies, Research and Theory for College and University Teachers. Boston, MA: Houghton-Mifflin. 